Exercise Physiology

\title{
Physical training attenuates right ventricular dysfunction in rats exposed to cigarette smoke
}

\author{
Paula G. Sant'Ana ${ }^{1}$ (1) , Adriano F. Maia ${ }^{2,3}$ (1) , Carmen Castardeli ${ }^{4}$ (D) , José Geraldo Mill ${ }^{4}$ (i) , Julien S. Baker ${ }^{5}$ (D) , \\ Danilo S. Bocalini ${ }^{2}$ (1) , Edson Castardeli ${ }^{1}(1)$

\begin{abstract}
${ }^{1}$ Universidade Federal do Espírito Santo, Centro de Educação Física e Esporte, Vitória, ES, Brasil; '2Universidade Federal do Espirito Santo, Laboratório de Fisiologia e Bioquímica Experimental, Vitória, ES, Brasil; ${ }^{3}$ Universidade Federal do Espírito Santo, Laboratório de Nutrição Esportiva, Vitória, ES, Brasil; ${ }^{4}$ Universidade Federal do Espírito Santo, Departamento de Fisiologia, Vitória, ES, Brasil, ${ }^{5}$ Hong Kong Baptist University, Faculty of Social Sciences,
\end{abstract} \\ Department of Sport and Physical Education, Centre for Health and Exercise Science Research, Kowloon Tong, Hong Kong, China
}

\author{
Associate Editor: Katia de Angelis. UNIFESP/São Paulo, Brasil.
}

\begin{abstract}
Aim: To evaluate the functional and morphological cardiac variables of rats exposed to chronic cigarette smoke (ECS) and to analyze the influence of exercise training on any cardiac remodeling. Methods: Male Wistar rats were assigned into four groups: control animals $(\mathrm{C}, \mathrm{n}=10)$; control trained rats $(\mathrm{CT}, \mathrm{n}=10)$, that underwent swimming physical training; ECS rats $(E, n=10)$, that received the smoke of 40 cigarettes/day; and ECS plus trained rats (TE, $\mathrm{n}=10$ ), that received the cigarette smoke plus the swimming training protocol, for 15 weeks. At the end of the experiment, theanimalsunderwenthemodynamicmeasurements oftherightventricle (RV)andmorphologicalexamination. Results: There was a decrease in the body weight of E, TE and CT groups $(\mathrm{p}<0.05)$. RV pressure (maximum systolic, diastolic initial and end-diastolic) was increased in the E and ET groups ( $<<0.05)$, while there was a decrease in RV maximum derivative pressure, $\mathrm{RV}$ minimum derivative pressure $(+\mathrm{dP} / \mathrm{dt}$ and $-\mathrm{dP} / \mathrm{dt})$ and systolic duration in the $\mathrm{TE}$ group $(\mathrm{p}<0.05)$. Heart rate increased in the $\mathrm{E}$ group $(\mathrm{p}<0.05)$. The lung weight/body weight ratio was higher in the TE group ( $\mathrm{p}=0.008$ ). Fluid retention was increased in the RV, left ventricle (LV) and lung of the $E$ group $(\mathrm{p}<0.001)$. Conclusion: ECS caused right ventricular dysfunction, pulmonary hypertension and cardiac remodeling. Physical training attenuated the effects of ECS for heart rate responses and the morphological variables of the RV, LV, and the lung.
\end{abstract}

Keywords: ventricular function; smoking; cardiac remodeling; exercise; swimming.

\section{Introduction}

Smoking is a risk factor for poor health and is the primary avoidable cause of death worldwide ${ }^{1-3}$. Studies have shown a strong relationship between smoking and the development of chronic obstructive pulmonary disease, lung cancer, bladder cancer, larynx cancer, inflammatory disease, endothelial injury, and cardiac remodeling with heart function impairment $t^{4-10}$. Acute stroke, angina pectoris, myocardial infarction, and even sudden death are among the cardiovascular effects caused by smoking ${ }^{1-3}$.

Few research studies using animal models have investigated the impacts of smoking on the right ventricles (RV) of the heart, however, the adaptive response to the functional overload in the left ventricle (LV) caused by smoking is known to cause structural and functional changes?

Unlike smoking, chronic aerobic training promotes functional and morphological adaptations in the cardiovascular system including the development of physiological cardiac hypertrophy, which leads to improvements such as increased contractile function, resting bradycardia, capillary vessels as well as decreased systolic arterial pressure, intrinsic cardiac changes, and heart vascularization ${ }^{10-13}$.
Thus, physical exercise may be an effective strategy used to prevent, reduce, or reverse the cardiac remodeling process caused by exposure to cigarette smoke (ECS). Therefore, this study sought to evaluate heart function and morphological variables of rats that were chronically exposed to cigarette smoke. A secondary aim was to analyze the influence of physical training on any cardiac remodeling caused by chronic ECS.

\section{Methods}

\section{Animals}

This study protocol followed the National Institutes of Health's Guidelines for the Care and Use of Laboratory Animals, and it was approved by the Animal Ethics Committee of our institution (Protocol \#032/2010). Male Wistar rats weighing between $200 \mathrm{~g}$ and $250 \mathrm{~g}$ were randomly distributed into four groups: Control $(\mathrm{C} ; \mathrm{n}=10)$ sedentary animals that did not undergo any treatment; trained $(\mathrm{T} ; \mathrm{n}=10)$ composed of trained animal that underwent a physical training protocol; sedentary animals 
exposed to cigarette smoke $(\mathrm{E} ; \mathrm{n}=10)$ and trained animals exposed to cigarette smoke TE $(\mathrm{n}=10)$. The animals received water $a d$ libitum and daily controlled feed so that the ingestion behavior of each group could be observed. Body weight was measured every week. Room temperature was kept at approximately at $22 \pm 2^{\circ} \mathrm{C}$, and 12-hour light-dark cycles were maintained for 15 weeks.

\section{Exposure to tobacco smoke}

Rats were exposed to cigarette smoke in a chamber (dimension: $89 \times 86 \times 55-\mathrm{cm})$ connected to a smoking device as described in other studies ${ }^{3,5,10,14}$. The smoke was drawn out of filtered commercial cigarettes (composition per unit: $1.1 \mathrm{mg}$ nicotine, $14 \mathrm{mg}$ tar, and $15 \mathrm{mg}$ carbon monoxide) with a vacuum pump and exhausted into the smoking chamber. During the first week, five cigarettes were used for 30 minutes (twice during the afternoon and 10 minutes apart from each other). Afterward, ten cigarettes were used during each session and the chronic cigarette smoke protocol was performed four times a day, twice in the morning and twice during the afternoon. Subsequently, 20 cigarettes were used in each smoking session, four times a day (30 $\mathrm{min}$ in the morning and $30 \mathrm{~min}$ in the afternoon) for fifteen weeks. The chamber carbon monoxide content was measured with a sensor Toxi Vision CO 860 (Biosystems, Prairieville, LA, USA). Additionally, the protocol ${ }^{3,5,10}$ choice especially had been addressed to the fact that this procedure had been considered such an important to promote great impact on carboxyhemoglobin, with similar levels of hard smokers.

\section{Physical exercise protocol}

The exercise protocol was performed by swimming training according to previous publications ${ }^{12,13}$. Briefly, a container filled with tap water ( 80 -cm deep) was warmed at $32 \pm 1^{\circ} \mathrm{C}$ by a feedback-controlled electric heating coil, and the water was maintained in continuous turbulence to provide for continuous exercise. For animal adaptation, the training session was limited to $10 \mathrm{~min}$ on the first day and increased by $10 \mathrm{~min}$ each day. After each swimming session, rats were gently toweled dry before they were returned to their cages. Rats swam for a total period of 15 weeks, $60 \mathrm{~min} /$ day, and 5 days/week.

\section{Evaluated parameters}

\section{Hemodynamic measurement}

Hemodynamic assessments were performed 15 weeks after the training protocol under appropriate anesthesia with $90 \%$ ketamine and $10 \%$ xylazine. Twenty-four hours after, the rats' last chronic cigarette smoke. A polyethylene catheter (PE 50) filled with heparin in a saline solution (HEPARIN SODIUM,
ARISTON, BRAZIL) was inserted into the right external jugular vein. The catheter was inserted into the right ventricle (RV) and tied to the vein using a cotton thread so that ventricular contractions did not move the catheter, thereby allowing recordings to be performed.

For the intraventricular pressure $(\mathrm{mmHg})$ assessment, the catheter in the RV was attached to a pressure transducer (TRI 21, LETICA SCIENTIFIC INSTRUMENTS, SPAIN) that was connected to a data acquisition system (BIOPAC, INC., MODEL MP100). This system facilitated the measurement of the following physiological variables possible: RV maximum systolic pressure $\left(\mathrm{RVSP}_{\max }\right)$, RV initial diastolic pressure (RVIDP), RV end-diastolic pressure (FDP), RV maximum $(+\mathrm{dP} / \mathrm{dt})$ and minimum $(-\mathrm{dP} / \mathrm{dt})$ derivative pressure $(\mathrm{mmHg} / \mathrm{s}), \mathrm{RV}$ systolic duration (RVSD), and heart rate (HR). The recordings were analyzed using Chart v. 7.0 (ADINSTRUMENTS INC. AUSTRALIA).

\section{Morphological parameters}

Following hemodynamic evaluations, the right and left ventricle and lungs were removed and weighed using an analytical precision scale (ELETRONIC BALANCE, FA 2140N, BIOPRECISA). The water content of the organs was obtained using the relationship between wet and dry weights. The right tibias were removed and measured using a caliper (MITUTOYO) in millimeters $(\mathrm{mm})$.

\section{Statistical analysis}

Analyses were performed using the SigmaStat, v. 3.5 (San Raphel, CA, USA). All data are expressed as mean \pm standard deviations (SD). The D'Agostino-Pearson and Levene tests were used to verify approximately normal statistic distributions and variance homogeneity, respectively. Comparisons between groups were performed by ANOVA two-way complemented by Tukey's multiple comparison test. Statistical significance was established at $\mathrm{p}<0.05$.

\section{Results}

Initial body mass was similar around all groups and did not show any significant differences among groups. However, as showed at $15^{\circ}$ week (figure 1A), similar body mass was found between $\mathrm{C}(440 \pm 8 \mathrm{~g})$, and $\mathrm{T}(407 \pm 11 \mathrm{~g})$ group that were higher $(\mathrm{F}=10.29 ; \mathrm{p}=0.0001) \mathrm{E}(361 \pm 14 \mathrm{~g})$ and ET $(372 \pm 10)$ and were not different from each other. Additionally, Figure 1B shows the area under the curve of groups differences of body mass development $(\mathrm{F}=306.7 ; \mathrm{p}=0.0001)$ were found around groups, indicating the influence on body weight gain on trained and smokes rats.

The morphological data may be visualized in table 2 . The highest RV weight by body weight (RV/BW) ratio was found on TE compared with the E group. T group exhibited a higher $\mathrm{RV} / \mathrm{BW}$ ratio than $\mathrm{C}$. The $\mathrm{RV}$ water content was higher in 
E compared with TE and $\mathrm{C}$ groups. The LV weight by body weight $(\mathrm{LV} / \mathrm{BW})$ ratio was higher on $\mathrm{T}$ compared with the $\mathrm{C}$ group. The $\mathrm{E}$ group displayed a higher $\mathrm{LV} / \mathrm{BW}$ ratio than $\mathrm{C}$. Additionally, the E group presented significantly higher water content on their LV content than the TE group. The lung weight by body weight (Lung/BW) ratio was greater for T compared with TE and C. E group displayed significantly higher water content on lungs compared with TE. C group had significantly longer tibias than the E group.

Table 2 shows the hemodynamic measurements. The values of HR of the ET group were similar to the $\mathrm{C}$ and $\mathrm{T}$ groups and all of them were lower compared with the E group. However, the values for the $\mathrm{T}$ group were lower than the $\mathrm{C}$ group. chronic cigarette smoke increased the RVSP ${ }_{\text {max }}$ of E compared with $\mathrm{C}$ as well as TE compared with the T group. The RVSP ${ }_{\max }$ of the $\mathrm{T}$ group was significantly decreased compared with the $\mathrm{C}$. RVFDP also significantly increased in the chronic cigarette smoke groups. The $+\mathrm{dP} / \mathrm{dt}$ of the TE group was lower than the E and T groups. Systolic duration significantly decreased on TE compared with the T group.
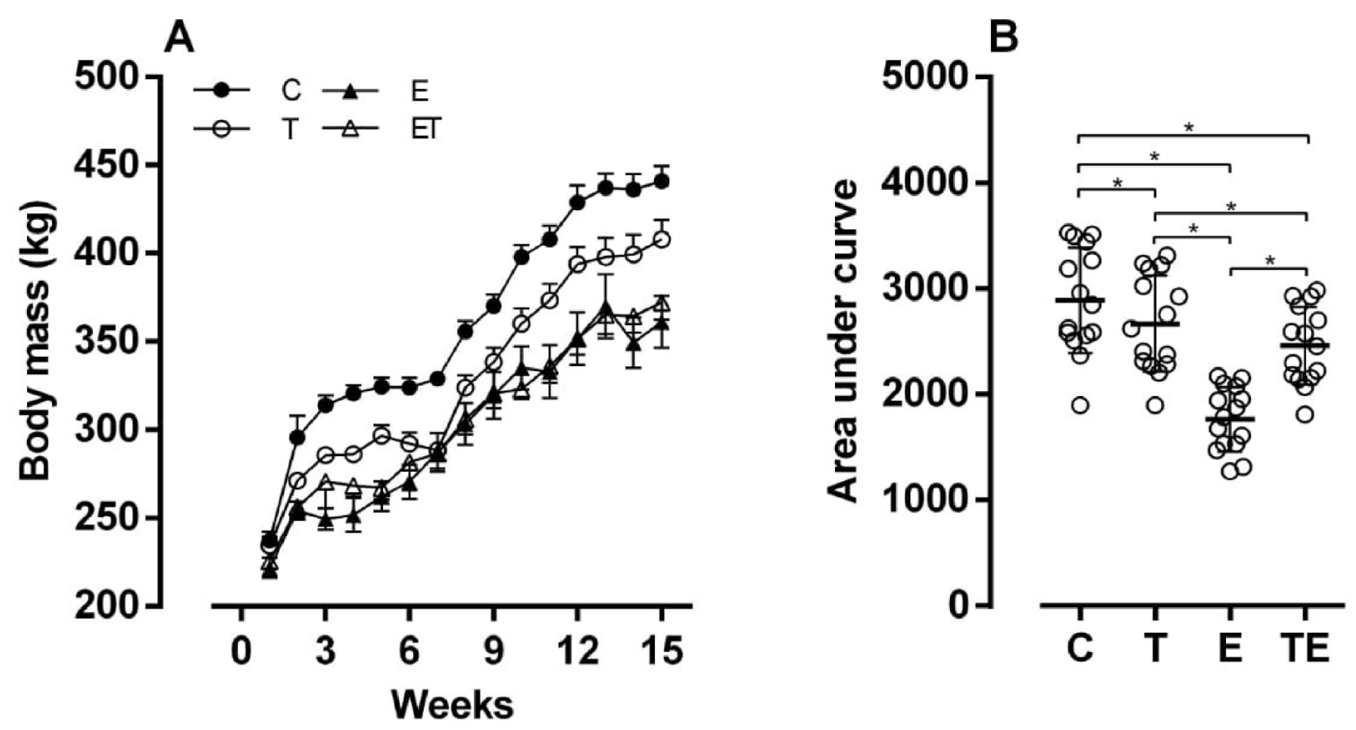

Figure 1 - Body mass development (Panel A) and area under curve of body mass development (Panel B) by control (C), trained (T), exposed to cigarette smoke (E) and trained and exposed to cigarette smoke (TE) groups. Values expressed as means \pm standard deviations. ${ }^{*} \mathrm{p}<0.001$.

Table 1 - Morphological data

\begin{tabular}{|c|c|c|c|c|c|c|c|}
\hline Group & $\begin{array}{l}\text { RV/BW } \\
\text { (mg/kg) }\end{array}$ & $\begin{array}{l}\mathrm{LV} / \mathrm{BW} \\
(\mathrm{mg} / \mathrm{kg})\end{array}$ & $\begin{array}{c}\text { Lung/BW (mg/ } \\
\text { kg) }\end{array}$ & $\begin{array}{l}\text { RV } \\
(\%)\end{array}$ & $\begin{array}{l}\mathrm{LV} \\
(\%)\end{array}$ & $\begin{array}{c}\text { Lung } \\
(\%)\end{array}$ & $\begin{array}{c}\text { Length of tibia } \\
(\mathrm{mm})\end{array}$ \\
\hline $\mathrm{C}$ & $0.51 \pm 0.03^{\mathrm{ab}}$ & $1.67 \pm 0.11^{\mathrm{a}}$ & $4.23 \pm 0.2^{\mathrm{a}}$ & $78.00 \pm 0.90^{\mathrm{a}}$ & $78.00 \pm 0.50^{\mathrm{a}}$ & $78.00 \pm 0.70^{\mathrm{a}}$ & $42.40 \pm 0.33^{\mathrm{a}}$ \\
\hline $\mathrm{T}$ & $0.63 \pm 0.03^{\mathrm{ab}}$ & $2.18 \pm 0.12^{\mathrm{b}}$ & $5.56 \pm 0.2^{b}$ & $78.30 \pm 0.80^{\mathrm{a}}$ & $77.90 \pm 0.40^{\mathrm{a}}$ & $78.00 \pm 0.80^{\mathrm{a}}$ & $41.90 \pm 0.33^{\mathrm{ab}}$ \\
\hline $\mathrm{E}$ & $0.50 \pm 0.03^{\mathrm{a}}$ & $2.07 \pm 0.11^{\mathrm{b}}$ & $4.59 \pm 03^{\mathrm{ab}}$ & $83.00 \pm 0.80^{\mathrm{b}}$ & $83.00 \pm 0.40^{\mathrm{b}}$ & $82.00 \pm 0.70^{\mathrm{b}}$ & $40.70 \pm 0.33^{\mathrm{b}}$ \\
\hline $\mathrm{TE}$ & $0.62 \pm 0.04^{\mathrm{b}}$ & $2.07 \pm 0.11^{\mathrm{ab}}$ & $4.57 \pm 0.2^{\mathrm{a}}$ & $79.0 \pm 0.60^{\mathrm{a}}$ & $79.00 \pm 0.60^{\mathrm{a}}$ & $79.00 \pm 0.70^{\mathrm{a}}$ & $40.80 \pm 0.31^{\mathrm{ab}}$ \\
\hline \multicolumn{8}{|l|}{ Effects } \\
\hline *Effect of ECS & $\begin{array}{l}F=0.177 \\
p=0.677\end{array}$ & $\begin{array}{c}F=0.0006 \\
p=0.979\end{array}$ & $\begin{array}{l}F=1.646 \\
p=0.210\end{array}$ & $\begin{array}{c}F=50.911 \\
p=0.001\end{array}$ & $\begin{array}{c}F=10.264 \\
p=0.003\end{array}$ & $\begin{array}{l}F=6.533 \\
p=0.016\end{array}$ & $\begin{array}{c}F=12.776 \\
p=0.001\end{array}$ \\
\hline$* *$ Effect of swimming & $\begin{array}{c}F=11.066 \\
p=0.002\end{array}$ & $\begin{array}{l}F=6.625 \\
p=0.015\end{array}$ & $\begin{array}{l}F=6.916 \\
p=0.014\end{array}$ & $\begin{array}{c}F=67.542 \\
p=0.001\end{array}$ & $\begin{array}{l}F=5.774 \\
p=0.023\end{array}$ & $\begin{array}{l}F=2.898 \\
p=0.099\end{array}$ & $\begin{array}{l}F=1.629 \\
p=0.212\end{array}$ \\
\hline ***Interaction ECS x Swimming & $\begin{array}{c}F=0.0001 \\
p=0.997\end{array}$ & $\begin{array}{l}F=1.515 \\
p=0.228\end{array}$ & $\begin{array}{l}F=7.367 \\
p=0.011\end{array}$ & $\begin{array}{c}F=76.881 \\
p=0.001\end{array}$ & $\begin{array}{l}F=1.526 \\
p=0.227\end{array}$ & $\begin{array}{l}F=8.753 \\
p=0.006\end{array}$ & $\begin{array}{l}F=2.650 \\
p=0.114\end{array}$ \\
\hline
\end{tabular}

Values expressed as means \pm standard deviations; of control $(\mathrm{C})$, trained $(\mathrm{T})$, exposed to cigarette smoke (E) and trained and exposed to cigarette smoke (TE) groups. RV/BW: right ventricular/body weight ratio. LV/PC: left ventricular/body weight ratio. Lung/ BW: lung/ body weight ratio. RV (\%): right ventricular water content. LV (\%): left ventricular water content. Lung (\%): water content.

*Effect of exposure to chronic cigarette smoke (ECS): $\mathrm{F}$ and p values in the analysis of two-way ANOVA.

**Effect of swimming: $\mathrm{F}$ and $\mathrm{p}$ values in the analysis of two-way ANOVA.

***Interaction of ECS and swimming: $\mathrm{F}$ and $\mathrm{p}$ values in the analysis of two-way ANOVA.

Different letters represent statistical differences $(\mathrm{p}<0.05)$. 
Table 2 - Hemodynamic measurement.

\begin{tabular}{|c|c|c|c|c|c|}
\hline Group & $\begin{array}{c}\text { HR } \\
\text { (bpm) }\end{array}$ & $\begin{array}{l}\text { RVSP }_{\text {max }} \\
(\mathrm{mmHg})\end{array}$ & $\begin{array}{l}\text { RVFDP } \\
(\mathrm{mmHg})\end{array}$ & $\begin{array}{c}+\mathrm{dP} / \mathrm{dt} \\
(\mathrm{mmHg} / \mathrm{s})\end{array}$ & $\begin{array}{c}-\mathrm{dP} / \mathrm{dt} \\
(\mathrm{mmHg} / \mathrm{s})\end{array}$ \\
\hline $\mathrm{C}$ & $225.85 \pm 7.83^{\mathrm{a}}$ & $32.41 \pm 0.74^{\mathrm{a}}$ & $7.08 \pm 0.39^{a}$ & $932.43 \pm 90.00^{\mathrm{a}}$ & $-1034.38 \pm 41.00^{\mathrm{a}}$ \\
\hline $\mathrm{T}$ & $223.91 \pm 7.80^{\mathrm{a}}$ & $29.13 \pm 0.74^{\mathrm{a}}$ & $7.36 \pm 0.39^{\mathrm{a}}$ & $945.51 \pm 90.00^{\mathrm{ac}}$ & $-886.44 \pm 41.00^{\mathrm{ac}}$ \\
\hline $\mathrm{E}$ & $259.27 \pm 7.83^{b}$ & $33.49 \pm 0.74^{\mathrm{b}}$ & $8.26 \pm 0.39^{b}$ & $1103.30 \pm 90.00^{\mathrm{a}}$ & $-1023.74 \pm 41.00^{\mathrm{a}}$ \\
\hline TE & $230.93 \pm 6.91^{\mathrm{a}}$ & $33.72 \pm 0.65^{\mathrm{b}}$ & $8.41 \pm 0.35^{\mathrm{b}}$ & $722.89 \pm 79.00^{\mathrm{c}}$ & $-695.46 \pm 37.00^{c}$ \\
\hline \multicolumn{6}{|l|}{ Effects } \\
\hline *Effect of ECS & $\begin{array}{l}F=7.053 \\
p=0.013\end{array}$ & $\begin{array}{c}F=15.417 \\
p=0.001\end{array}$ & $\begin{array}{l}F=8.374 \\
p=0.008\end{array}$ & $\begin{array}{l}F=0.087 \\
p=0.770\end{array}$ & $\begin{array}{l}F=6.107 \\
p=0.020\end{array}$ \\
\hline **Effect of swimming & $\begin{array}{l}F=3.954 \\
p=0.057\end{array}$ & $\begin{array}{c}\mathrm{F}=4.462 \\
\mathrm{p}=0.044\end{array}$ & $\begin{array}{l}\mathrm{F}=0.293 \\
\mathrm{p}=0.593\end{array}$ & $\begin{array}{l}F=4.398 \\
p=0.046\end{array}$ & $\begin{array}{c}F=34.073 \\
p=0.001\end{array}$ \\
\hline$* * *$ Interaction ECS x Swimming & $\begin{array}{l}F=3.004 \\
p=0.095\end{array}$ & $\begin{array}{l}F=5.868 \\
p=0.023\end{array}$ & $\begin{array}{l}F=0.029 \\
p=0.866\end{array}$ & $\begin{array}{l}\mathrm{F}=5.052 \\
\mathrm{p}=0.033\end{array}$ & $\begin{array}{l}F=4.886 \\
p=0.036\end{array}$ \\
\hline
\end{tabular}

Values expressed as means \pm standard deviations; of control $(\mathrm{C})$, trained $(\mathrm{T})$, exposed to cigarette smoke (E) and trained and exposed to cigarette smoke (TE) groups. RVSP ${ }_{\max }$ : right ventricle maximum systolic pressure. HR: heart rate. RVFDP: right ventricle end diastolic pressure. $+\mathrm{dP} / \mathrm{dt}$ : maximum derivative of right ventricle pressure. $-\mathrm{dP} / \mathrm{dt}$ : minimum derivative of right ventricle pressure.

*Effect of exposure to chronic cigarette smoke (ECS): $\mathrm{F}$ and $\mathrm{p}$ values in the analysis of two-way ANOVA.

**Effect of swimming: $\mathrm{F}$ and $\mathrm{p}$ values in the analysis of two-way ANOVA.

***Interaction of ECS and swimming: $\mathrm{F}$ and $\mathrm{p}$ values in the analysis of two-way ANOVA.

Different letters represent statistical differences $(p<0.05)$.

\section{Discussion}

The results revealed that chronic cigarette smoke caused significant cardiovascular function and structural changes in rats. The decreased body mass observed among chronic cigarette smoke animals indicates that smoking caused changes in the development curve of these animals. Reis Junior et al. ${ }^{15}$ found similar results suggesting that the weight loss associated with cigarette smoke exposure involves appetite-modulating neuronal mechanisms. One possible explanation for this result is the influence of nicotine, one of the major addictive components in cigarette smoke ${ }^{10}$. A study of nicotine administration to animals showed a $10 \%$ increase in energy expenditure and the release of norepinephrine and serotonin, which inhibit appetite ${ }^{14}$.

Pulmonary hypertension is defined as an increase of $\mathrm{RVSP}_{\max }$ above $25 \mathrm{mmHg}^{16}$. Groups $\mathrm{E}$ and TE displayed RVSP ${ }_{\max }$ values above $30 \mathrm{mmHg}$, which indicates the development of pulmonary hypertension. In turn, the development of pulmonary hypertension suggests changes in RV afterload due to increased pulmonary arterial vascular resistance. A high afterload demands that the RV pumps more blood into the pulmonary circulation. The RV pumps blood with more force into the lungs to perform the gas exchange and subsequently increases heart energy expenditure ${ }^{16,17}$, which remodels the $\mathrm{RV}^{4,16-19}$.

In addition to increased $\mathrm{RVSP}_{\max }$, the $\mathrm{E}$ group showed increased $\mathrm{RV}$ water content and water retention in the lungs, both of which indicate pulmonary congestion ${ }^{12}$. Furthermore, the water retention in the RV of the E group might have caused pulmonary hypertension, which is subsequently involved in the cardiac remodeling mechanism. There is no consensus about the hypertrophy mechanism involved in cardiac hypertrophy, however, the hypoxia caused carbon monoxide ${ }^{20,21}$ and nicotine $^{22,23}$ as well as are increased on $\operatorname{RVSP}_{\text {max }}{ }^{8}$. However, the knowledge about cardiac hypertrophy trigger to left ventricle cannot be extrapolated to the right ventricle ${ }^{24,25}$ mainly in presence of pulmonary hypertension. Additionally, the reasons for it are unclear and shown to be investigated, nevertheless, one possible cause to promote right cardiac hypertrophy is the address to cardiac compensation due to increased afterload and maintenance of cardiac output.

The RVSP $_{\text {max }}$ of the TE group was higher than that of T and like the E group. This finding suggests that the exercise load/ intensity was not sufficient to attenuate the deleterious effects of chronic cigarette smoke, maybe to not promote the effect of the RVSP ${ }_{\text {max }}$ decrease. Nevertheless, the benefits promoted by exercise were significant in the TE group with regard to the decrease in water content of the RV, LV, and lungs, thereby reducing pulmonary congestion.

Previous studies ${ }^{11,12}$ with sedentary and trained spontaneously hypertensive rats observed that physical training attenuated the effects of the cardiac remodeling process caused by hypertension, reduced systolic arterial pressure, and developed hypertrophy with functional improvement. However, sedentary SHRs developed cardiac remodeling.

The chronic cigarette smoke caused hemodynamic changes that affect the cardiac remodeling process by causing changes in the RV chamber filling and relaxation pressures. Gaynor et al. ${ }^{26}$ showed that the compensatory response of the $\mathrm{RV}$ to chronic pressure overload increases contractility but impairs diastole. However, the changes caused by low-intensity chronic aerobic exercises decreased the sympathetic tonus of the heart and engendered beneficial effects such 
as resting bradycardia: a decrease in cardiac output and pressure $^{11,12,27}$ Studies with SHRs revealed beneficial effects of chronic training, with significant reductions in systolic and diastolic pressures ${ }^{12,28}$. Azevedo et al. ${ }^{29}$ studied cardiac remodeling patterns and found that animals with chronic cigarette smoke displayed at least one of four patterns of geometrical changes: normal, eccentric hypertrophy, concentric hypertrophy, and concentric remodeling. The same phenomenon was observed in clinical trials using an arterial hypertension model ${ }^{30}$. Accordingly, the hemodynamic (RVSP $_{\text {max }}$ and RVFDP) changes observed in our studies and the development of the cardiac remodeling process caused by chronic cigarette smoke. Furthermore, this finding suggests that chronic cigarette smoke alters venous return or the distension capacity of the ventricular wall during diastole ${ }^{31}$. Physical training did not reduce RVFDP, although evidence exists that exercise decreases FDP ${ }^{11,12}$.

The maximum derivative of RV pressure $(+\mathrm{dP} / \mathrm{dt})$, which represents myocardial contractility ${ }^{32-38}$ decreased in the TE group, which indicates that the combination of chronic cigarette smoke and physical training impaired the contractile function of the RV. Furthermore, the increased RVFDP found in the TE group might not only reflect an RVSP dysfunction but also impairment in cardiac contractility ${ }^{33}$, as shown by the lower $+\mathrm{dP} / \mathrm{dt}$ in the TE group. Unlike our findings, Reis Junior et al. ${ }^{15}$ found high $+\mathrm{dP} / \mathrm{dt}$ values for animals with CHRONIC CIGARETTE SMOKE . Changes in the minimum derivative of the RV pressure $(-\mathrm{dP} / \mathrm{dt})$ were found among the TE group, which suggests that the ability of the RV to relax ${ }^{31,32,35}$ contributes to RV dysfunction.

HR was lower in the TE group, which indicates that training promoted beneficial cardiac changes that decreased HR, which agrees with the literature ${ }^{11,27,35,36}$. In addition, the increase in HR was lower for TE compared with the E group. This result shows how effective physical training is at attenuating the effects of chronic cigarette smoke and reducing HR by over $30 \mathrm{bpm}$ compared with the TE group. The example illustrates the importance of decreasing HR for the animals in this study.

Normotensive rats trained to swim over 15 weeks (compared with SHRs) showed that the former rats displayed better cardiac function, a lower HR, and the subsequent development of (physiological) hypertrophy. Conversely, the SHRs developed cardiac hypertrophy due to hypertension and were classified as pathological with decreases in heart function and increases in resting HR and ejection volume ${ }^{10-12,36}$.

In summary, chronic cigarette smoke caused RV dysfunction and resulted in the development of pulmonary hypertension, with changes in hemodynamic variables and cardiac remodeling. The intensity and load of physical training determined by the swimming protocol were not enough to attenuate the aggressive effects of chronic cigarette smoke regarding the functional parameters; however, a positive influence was found regarding lung and heart morphological parameters. Thus, training can attenuate the effects of chronic cigarette smoke with regard to HR and morphological variables of the RV, LV, and lung.

\section{References}

1. Cohn JN, Bristow MR, Chien KR, Colucci WS, Frazier OH, Leinwand LA, et al. Report of the National Heart Lung and Blood Institute Special Emphasis Panel on Heart Failure Research. Circulation. 1997; 95: 766-70.

2. U.S. Department of Health and Human Services. Reducing Tobacco Use. A Report of the Surgeon General. Atlanta: U.S. Department of Health and Human Services, Centers for Disease Control and Prevention, National Center for Chronic Disease Prevention and Health Promotion, Office on Smoking and Health, 2000c: 198. (p. 198, updated for this publication by the Centers for Disease Control and Prevention, 2004).

3. Zornoff LAM, Matsubara BB, Matsubara LS, Minicucci MF, Azevedo PS, Campana AO, et al. Cigarette smoke exposure intensifies the ventricular remodeling process following myocardial infarction. Arq Bras Cardiol. 2006; 86: 276-82.

4. Edward P, Chen PE, Craig MD, Bittner, BH, Davis, DR, Trigt VP. Pharmacological strategies for improving diastolic dysfunction in the setting of chronic pulmonary hypertension. J Am Heart Assoc Circ. 1998; 97: 1606-12.

5. Castardeli E, Paiva SA, Matsubara BB, Matsubara LS, Minicucci MF, Azevedo OS, et al. Chronic cigarette smoke exposure results in cardiac remodeling and impaired ventricular function in rats. Arq Bras Cardiol. 2005; 84(4): 320-4.

6. Paiva SA, Novo R, Matsubara BB, Matsubara LS, Azevedo PS, Minicucci MF, et al. Beta-carotene attenuates the paradoxical effect of tobacco smoke on the mortality of rats after experimental myocardial infarction. J Nutrition. 2005; 135(9): 2109-13.

7. Denipote F, Ardisson LP, Azevedo PS, Minicucci MF, LimaLeopoldo AP, et al. Influence of taurine on cardiac remodeling induced by tobacco smoke exposure. Cell Physiol Biochem. 2011; 27: 291-8.

8. Rafacho BP, Azevedo PS, Polegato BF, Fernandes AA, Bertoline $\mathrm{MA}$, et al. Tobacco smoke induces the ventricular remodeling associated with an increase in NADPH oxidase activity. Cell Physiol Biochem. 2011; 27: 305-12.

9. Smith CJ, Fisher TH. Particulate and vapor phase constituents of cigarette mainstream smoke and risk of myocardial infarction. Atherosclerosis 2001; 158: 257-67.

10. Paiva SA, Zornoff LA, Okoshi MP, Okoshi K, Cicogna AC, Campana AO. The behavior of cardiac variables in animals exposed to cigarette smoke. Arq Bras Cardiol. 2003; 81(3): 221-8.

11. Scheuer J. Physical training and intrinsic cardiac adaptations. Circulation. 1973; 47: 677-80.

12. Lemitsu M, Miyauchi T, Maeda S, Sakai S, Kobayashi T, Fujii N, et al. Physiological and pathological cardiac hypertrophy induce different molecular phenotypes in rats. Am J Physiol Regulatory Integrative Comp Physiol. 2001; 281: 2029-36.

13. Portes LA, Tucci PJF. O treinamento físico por natação atenua o remodelamento miocárdico e congestão pulmonar em ratas Wistar com insuficiência cardíaca secundária a infarto do miocárdio. Arq Bras Cardiol. 2005; 87(1): 57-8.

14. Wang X-D, Liu C, Bronson RT, Smith DE, Krinsky NI, Russel RM. Retinoid signaling and activator protein-1 expression in ferrets given b-carotene supplements and exposure to tobacco smoke. J Natl Cancer Inst. 1999; 91: 60-6. 
15. Reis Junior D, Sales BD, Antonio EL; Tonicelo R, Jorge SA; Abreu LC. Hipertrofia do miocárdio e alteração hemodinâmica em ratos expostos à fumaça de cigarro. ConScien Saúde. 2011; 10(4): 614-20.

16. 16 Hemnes AR, Champion HC. Right heart function and hemodynamics in pulmonary hypertension. Int J Clin Pract. 2008; 62: 11-9.

17. Pokreisz1 P, Marsboom G, Janssens S. Pressure overload-induced right ventricular dysfunction and remodeling in experimental pulmonary hypertension: The right heart revisited. Eur Soc Cardiol. 2007; 12(18): 75-84.

18. Szabó G, Soós P, Bährle S, Radovits T, Weigang E, Kékesi V, et al. The adaptation of the right ventricle to increased afterload in the chronically volume overload heart. The Annals of Thoracic Surgery. 2006; 82(3): 989-95.

19. Castardeli E, Duarte RD, Minicucci FM, Azevedo SP, Matsubara BB, Matsubara SL, Álvaro O, et al. Tobacco-smoke-induced left ventricular remodeling is not associated with metalloproteinase-2 or -9 activation. Eur J Heart Failure. 2007; 9: 1081-85.

20. Mirza A, Eder V, Rochefort GY, Hyvelin JM, Machet MC, Fauchier L, et al. CO inhalation at dose corresponding to tobacco smoke worsens cardiac remodeling after experimental myocardial infarction in rats. Toxicol Sci. 2005; 85(2): 976-82.

21. Sørhaug S, Steinshamn S, Nilsen OG, Waldum HL. Chronic inhalation of carbon monoxide: effects on the respiratory and cardiovascular system at doses corresponding to tobacco smoking. Toxicol. 2006; 228(2-3): 280-90.

22. Villarreal FJ, Hong D, Omens J. Nicotine-modified postinfarction left ventricular remodeling. Am J Physiol Heart Circ Physiol. 1999; 276: H1103-H6.

23. Elliott BM, Faraday MM, Grunberg NE. Effects of nicotine on heart dimensions and blood volume in male and female rats. Nicotine Tob Res. 2003; 5(3): 341-48.

24. Bogaard HJ, Abe K, Vonk Noordegraaf A, Voelkel NF. The right ventricle under pressure: cellular and molecular mechanisms of right-heart failure in pulmonary hypertension. Chest. 2009; 135(3): 794-804.

25. Haddad F, Doyle R, Murphy DJ, Hunt SA. Right ventricular function in cardiovascular disease, part II: pathophysiology, clinical importance, and management of right ventricular failure. Circulation. 2008; 117(13): 1717-31.

26. Gaynor SL, Maniar SH, Bloch BJ, Steendijk P, Moon RM. Right atrial and ventricular adaptation to chronic right ventricular pressure overload. Circulation. 2005; 112: 212-218.

27. Mill JG; Vassalo DV. Hipertrofia cardíaca. Rev Bras Hipert. 2001; 8: 63-75.

28. Negrão CE, Urbana PM; Rondon B. Exercício físico, hipertensão e controle barorreflexo da pressão arterial. [Physical exercise, hypertension, and blood pressure baroreflex control. Rev Bras Hipert. 2001; 8(1): 89-95.

29. Azevedo PS, Minicucci MF, Matsubara BB, Matsubara LS, Duarte DR, Paiva SAR, et al. Padrão de remodelação cardíaca e função ventricular em ratos expostos à fumaça de cigarro. Arq Bras Cardiol. 2010; 94(2): 224-8.

30. Dávila DF, Donis JH, Odreman R, Gonzalez M, Landaeta A. Patterns of left ventricular hypertrophy in essential hypertension:
Should echocardiography guide pharmacological treatment? Int J Cardiol. 2008; 124(2): 134-8.

31. Zornoff MLA, Cicogna CA, Paiva RAS, Spadaro J. Remodeling and its impact on progressive ventricular dysfunction. Rev Soc Cardiol. 2002; 12(3): 371-378.

32. Okoshi MP, Okoshi K, Pai VD, Pai-Silva MD, Matsubara LS, Cicogna AC. Mechanical, biochemical, and morphological changes in the heart from chronic food-restricted rats. Can J Physiol Pharm. 2001; 79(9): 754-60.

33. Okoshi K, Fioretto JR, Bonatto RC, Trovarelli MT, Tucci PJF. Influência da elevação da pressão diastólica do ventrículo esquerdo sobre os valores da primeira derivada temporal da pressão ventricular (dp/dt). Arq Bras Cardiol. 1999; 73(1): 37-41.

34. Ibrahim M, Navaratnarajah M, Siedlecka U, Rao C, Dias P, Moshkov AV, Gorelik J, Yacoub MH. 1, Terracciano CM. Mechanical unloading reverses transverse tubule remodeling and normalizes local $\mathrm{Ca}^{+2}$-induced $\mathrm{Ca}^{+2}$ release in a rodent model of heart failure. Eur J Heart Failure. 2012; 14: 571-80

35. Medeiros A, Gianolla RM, Bacurau RFP, Rosa, LFBC, Negrão CE, Brum PC. Efeito do treinamento físico com natação sobre o sistema cardiovascular de ratos normotensos. Rev Paul Educ Fis. São Paulo. 2000; 14(1): 7-15.

36. Brito F, Campos KN, Oliveira HÁ, Fernandes J, Silva CAM, Gaio E, et al. Hemodynamic effects of experimental acute right ventricular overload. Arq Bras Cardiol. 2011; 96: 284-91.

\section{Acknowledgments}

This work was supported by grants from the Fundação de Amparo à Pesquisa e Inovação do Espírito Santo (grant number 519/2020 and $84417625 / 2018$ ) fellowships granted to study publication and development. The fund providers had no role in the decision to publish nor in the preparation of the paper.

\section{Corresponding author}

Edson Castardeli

Physical Education and Sport Center.

Federal University of Espirito Santo, Vitoria, Brazil. Av. Fernando Ferrari, 514 Goiabeiras, Vitória - ES, 29060-220.

Email: castardeli@gmail.com

Manuscript received on July 6, 2020

Manuscript accepted on September 11, 2020

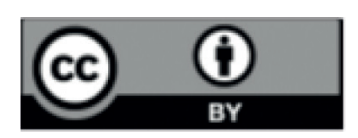

Motriz. The Journal of Physical Education. UNESP. Rio Claro, SP, Brazil - eISSN: 1980-6574 - under a license Creative Commons - Version 4.0 